\title{
Acute hiatal hernia after Heller's operation
}

\author{
MY RABAU, I AVIGAD, A CZERNIAK, Y LIBERMAN, I WOLFSTEIN
}

From the Department of Surgery and the Thoracic Surgical Unit, Chaim Sheba Medical Center, Sackler School of Medicine, Tel-Aviv University, Israel

A modified Heller's operation is the surgical treatment of choice for oesophageal achalasia. Oesophageal reflux (with or without hernia) has been reported as an infrequent complication of this operation. However, acute diaphragmatic hernia after Heller's operation is a rare complication. Routine anatomical restoration of the hiatus upon completion of the oesophagomyotomy will further reduce its occurrence. Once the diagnosis has been made, surgery is indicated to prevent additional complications.

\section{Case report}

A 60-year-old woman was operated on for achalasia of 10 years' duration. Routine transthoracic oesophagomyotomy was performed. The oesophageal muscle was divided longitudinally for $7 \mathrm{~cm}$, the lower end of the incision extending $1 \mathrm{~cm}$ into the cardia. Minimal division of the oesophageal hiatus was performed, which did not necessitate further repair. A nasogastric tube and a thoracic drainage tube were installed. The postoperative course in the first 48 hours was uneventful and the chest radiograph was satisfactory. The thoracic and nasogastric tubes were withdrawn. A few hours later, the patient complained of epigastric fullness and pain, accompanied by mild respiratory distress. A nasogastric tube was reinserted and a large amount of air was evacuated from the stomach. These symptoms recurred 24 hours later when the nasogastric tube was again removed. At this stage great difficulty was encountered in the insertion of the nasogastric tube. Chest radiographs revealed an elevated left diaphragm and dilatation of the stomach. Barium swallow demonstrated diaphragmatic herniation and torsion of the stomach (figure). The patient was reoperated on through an abdominal incision. A paraoesophageal hernia through the oesophageal hiatus was discovered, the spleen and half of the stomach having herniated into the chest cavity. Reduction of the abdominal viscera was performed, and an anterior closure of the hiatal defect with fixation of the stomach to the anterior abdominal wall by a gastrostomy were carried out. The postoperative course was uneventful.

\section{Discussion}

Acute postoperative hiatal hernia is a rare complication of Heller's operation. ${ }^{12}$ Frobese $^{3}$ suggested that the hernia

Address for reprint requests: Dr I Wolfstein, Department of Surgery, Chaim Sheba Medical Center, Tel Hashomer, Israel.

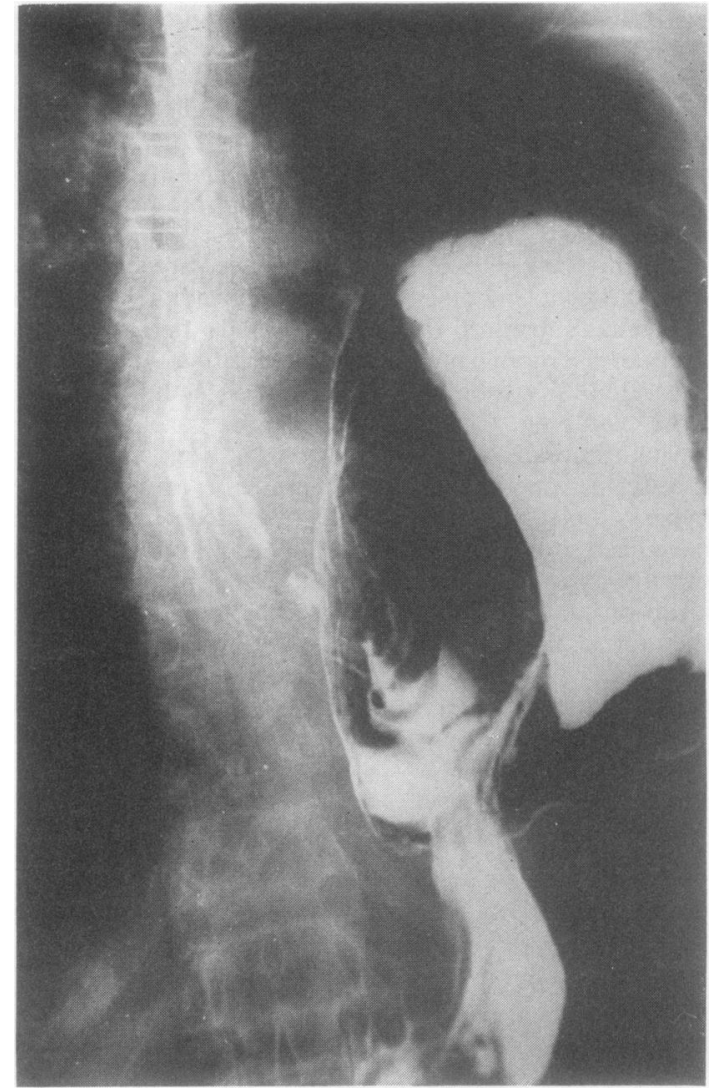

Figure Barium swallow demonstrating diaphragmatic herniation and torsion of the stomach.

occurs as a result of disruption of the oesophageal hiatus at operation and therefore recommended a routine anatomical restoration of the hiatus and cardiophrenic ligament upon completion of the procedure. Others advise hiatal repair after transabdominal correction of : achalasia, ${ }^{4}$ while reconstruction of the hiatus when operating by the transthoracic route is recommended only when a widened hiatus or diaphragmatic hernia coexist. ${ }^{5}$

Contrary to the cases reported by Frobese ${ }^{3}$ in which a $\stackrel{\mathbb{Q}}{\mathscr{Q}}$ sliding hiatal hernia occurred, in our case, as in the cases presented by Fletcher, ${ }^{1}$ a paraoesophageal hernia devel- 
oped, the cardio-oesophageal junction remaining below the diaphragm (figure). A possible mechanism which could explain the herniation is transient vagal trauma during the myotomy leading to delayed gastric emptying and thence gastric dilatation. The dilated stomach herniated through the oesophageal hiatus which was probably partially disrupted at the time of operation. This supports Frobese' ${ }^{3}$ advice for a routine anatomical restoration of the hiatus upon completion of the oesophagomyotomy. Once the diagnosis has been made, operation is indicated in order to avoid gastric torsion with possible gastric necrosis, ${ }^{2}$ or oesophageal perforation from acute obstruction at the cardioesophageal junction and increased pressure on the unsupported oesophageal mucosa at the myotomy site. ${ }^{1}$

\section{References}

${ }^{1}$ Fletcher PR. Acute hiatal hernia with oesophageal perforation following Heller's operation. Br J Surg 1978;65: 486-8.

${ }^{2}$ Rees JR, Thorbjarnarson B, Barnes WH. Achalasia: results of operation in 84 patients. Ann Surg 1970;171: 195-201.

${ }^{3}$ Frobese AS, Stein GN, Hawthorne HR. Hiatal hernia as a complication of the Heller operation. Surgery 1961; 49:599-605.

${ }^{4}$ Nemir P, Wallace HW, Fallahnegad M. Diagnosis and surgical management of benign disease of the oesophagus. Current Probl Surg 1976;13:51-3.

${ }^{5}$ Ellis FH, Kiser JC, Schlegel JF. Oesophagomyotomy for oesophageal achalasia: experimental clinical and manometric aspects. Ann Surg 1967;166:640-56.

\section{The Fourth Congress of the International Society for}

\section{Aerosols in Medicine will be held from 9-11 June 1982}

in Brno, Czechoslovakia. Additional information may be obtained

from Professor Vyskočil, Medical Faculty Hospital, CS-65691 Brno,

Pekařská 53, Czechoslovakia. (Telephone Brno 315). 